\section{P23 Q/A METHOD -A NOVEL WAY OF ASSESSING PULMONARY ARTERY STIFFNESS IN COPD USING CARDIAC MRI}

'S Saikia, ${ }^{1} \mathrm{NS}$ Gale, ${ }^{2} \mathrm{JCL}$ Rodrigues, ${ }^{3} \mathrm{RG}$ Wise, ${ }^{2} \mathrm{C}$ Bucciarelli-Ducci, ${ }^{1} \mathrm{JR}$ Cockcroft, 'DJ Shale. 'Wales Heart Research Institute, School of Medicine, Cardiff University, Cardiff, UK; ${ }^{2}$ Bristol Heart Institute, University Hospitals Bristol NHS Foundation Trust, Bristol, UK; ${ }^{3}$ Cardiff University Brain Research Imaging Centre, School of Psychology, Cardiff University, Cardiff, UK

\subsection{6/thoraxjnl-2015-207770.160}

Background Pulmonary artery distensibility and pulsatility has been studied in patients with COPD using cardiac MRI (CMRI). ${ }^{1}$ However, pulmonary artery pulse wave velocity (PAPWV) using the 'QA'method ${ }^{2}$ in CMRI has not been studied in this population. We hypothesised that patients with COPD have a higher PA-PWV compared to healthy individuals.

Methods This interim analysis includes 23 COPD and 12 healthy volunteers (current or ex-smokers free from respiratory disease). All participants underwent spirometry to measure FeV1, FVC and their ratio, oxygen saturations, heart rate, peripheral mean arterial pressure (MAP), 6-minute-walk-distance (6MWD) and cardiac MRI to measure PA-PWV.

MRI studies were performed using a 3.0T GE Signa HDx MRI scanner (GE Healthcare). Phase-contrast cross-sectional images of the pulmonary artery using steady-state free precession sequence were obtained, approximately $2 \mathrm{~cm}$ above the pulmonary valve, under free-breathing conditions.

Results Patients with COPD and the healthy individuals were similar in age and gender (Table 1). Patients with COPD had impaired lung function, greater PA-PWV $(3.37 \pm 0.62$ vs $1.4 \pm$ $\left.0.4, \mathrm{p}=<0.001^{*}\right)$, heart rate and mean arterial pressure than the healthy individuals. Male patients with COPD had greater PA-PWV $(3.63 \pm 0.45)$ than females $(3.11 \pm 0.59) \mathrm{p}=0.042$. PA-PWV did not relate to age, lung function, resting oxyyen saturations, heart rate or peripheral MAP.

\begin{tabular}{llll} 
Abstract P23 Table 1 & & \\
\hline & $\begin{array}{l}\text { COPD } \\
(\mathbf{n}=23)\end{array}$ & CONTROLS $(\mathbf{n}=12)$ & P-value \\
& $65.8 \pm 7.3$ & $66.8 \pm 7.1$ & 0.713 \\
\hline AGE (yrs) & $11: 12$ & $6: 6$ & 0.903 \\
GENDER (male:female) & $0.55 \pm 0.14$ & $0.75 \pm 0.06$ & $<0.001$ \\
FEV ${ }_{1 / \text { FVC (L) }}$ & $59.2 \pm 17.6$ & $105.8 \pm 12.5$ & $<0.001$ \\
FEV $_{1} \%$ predicted & $39.0 \pm 29.9$ & $12.2 \pm 8.6$ & $<0.001$ \\
SMOKING (pack years) & $68(9)$ & $62(7)$ & 0.034 \\
Resting Heart Rate (bpm) & $100.1 \pm 9.7$ & $95.6 \pm 10.5$ & 0.236 \\
Peripheral MAP (mmHg) & $3.37 \pm 0.6$ & $1.41 \pm 0.4$ & $<0.001$ \\
PA-PWV (m/s) & $388.2 \pm 127.7$ & $536.8 \pm 49.9$ & $<0.001$ \\
6MWT (m) & & & \\
\hline
\end{tabular}

Conclusion Pulmonary artery PWV measured using CMRI 'QA' method showed that COPD patients have a stiffer pulmonary artery than healthy individuals. Further analysis will investigate the association between pulmonary artery stiffness and cardiac function.

\section{REFERENCES}

1 Liu C-Y, Jiang R, Dashnaw S, et al. Pulmonary artery stiffness in chronic obstructive pulmonary disease (COPD) - the MESA COPD study. JCMR 2011;13(Suppl 1): P73

2 Peng H-H, Chung HW, Yu HY, Tseng WY. Estimation of pulse wave velocity in main pulmonary artery with phase contrast MRI: preliminary investigation. JMRI 2006:24:1303-1310

\section{P24 UNDERUSE OF BETA-BLOCKERS IN PATIENTS WITH HEART FAILURE AND COPD}

${ }^{1} \mathrm{D}$ Skinner, ${ }^{2} \mathrm{~B}$ Lipworth, ${ }^{3} \mathrm{G}$ Devereux, ${ }^{4} \mathrm{~V}$ Thomas, ${ }^{5} \mathrm{~J} \mathrm{Ling,}{ }^{6} \mathrm{~J}$ Martin, ${ }^{1} \mathrm{~V}$ Carter, ${ }^{5} \mathrm{D}$ Price. ${ }^{1}$ Optimum Patient Care, Cambridge, UK; ${ }^{2}$ Scottish Centre for Respiratory Research, University of Dundee, Dundee, UK; ${ }^{3}$ Department of Child Health, University of Aberdeen, Aberdeen, UK; ${ }^{4}$ Cambridge Research Support, Cambridge, UK; ${ }^{5}$ Observational and Pragmatic Research Institute, Singapore, Singapore; ${ }^{6}$ Research in Real Life, Cambridge, UK

\subsection{6/thoraxjnl-2015-207770.161}

Introduction and objectives Cardiovascular comorbidity is common in COPD. Retrospective health informatics studies have shown putative benefits of beta-blockers (BB) in reducing both mortality and exacerbations in COPD. ${ }^{1} \mathrm{BB}$ are established in heart failure (HF) guidelines including those patients who have concomitant COPD. However, there remain concerns regarding bronchoconstriction in COPD even with cardio-selective BB. For example, $55 \%$ of patients with COPD, who had a myocardial infarction (MI), were not prescribed a $\mathrm{BB}^{2}$ We wished to assess the use of BB for patients with HF who also have COPD.

Methods The Optimum Patient Care Research Database was used to identify QOF codes for 104,945 patients with COPD, 24,413 with HF and 13,421 with both conditions, where there was at least 1 year of data. We evaluated co-prescribing of $\mathrm{BB}$ with either ACE-inhibitor (ACEI) or Angiotensin-2 receptor blockers (ARB) in patients with HF/COPD and their association with inhaler therapy. Heart failure treatments were compared between groups using multinomial logistic regression.

Results In patients with HF/COPD, mean age was 79 years, $60 \%$ males and $27 \%$ had prior MI. $21.6 \%$ of patients with HF and $\operatorname{COPD}(\mathrm{n}=2,984)$ were taking a $\mathrm{BB}$ in conjunction with either ACEI/ARB as compared to $42.2 \%$ of patients with HF alone $(\mathrm{n}=10,303)(\mathrm{p}<0.001)$. In HF/COPD patients on triple inhaler therapy with ICS/LABA/LAMA there were $46.5 \%$ taking ACEI/ARB without $\mathrm{BB}(\mathrm{n}=1,292)$ verses $29.3 \%$ taking ACEI/ $\mathrm{ARB}$ with $\mathrm{BB}(\mathrm{n}=813)$ (odds ratio $[\mathrm{OR}]=1.59,95 \%$ CI 1.46 , $1.74, \mathrm{p}<0.001)$. Corresponding figures for those patients on dual inhaler therapy with ICS/LABA were $47.3 \%(\mathrm{n}=1,275)$ verses $22.2 \%(\mathrm{n}=599)$ respectively $(\mathrm{OR}=2.13,95 \%$ CI 1.93 , 2.35, $\mathrm{p}<0.001)$.

Conclusions Taken together these data therefore provide strong evidence of an unmet need in COPD patients who should be prescribed beta-blockers more often for concomitant HF.

\section{REFERENCES}

1 Short PM, Lipworth SI, Elder DH, Schembri S, Lipworth BJ. Effect of beta blockers in treatment of chronic obstructive pulmonary disease: a retrospective cohort study. BMJ 2011:342:d2549

2 Quint JK, Herrett E, Bhaskaran K, et al. Effect of $\beta$ blockers on mortality after myocardial infarction in adults with COPD: population based cohort study of UK electronic healthcare records. BMJ 2013:347:f6650 